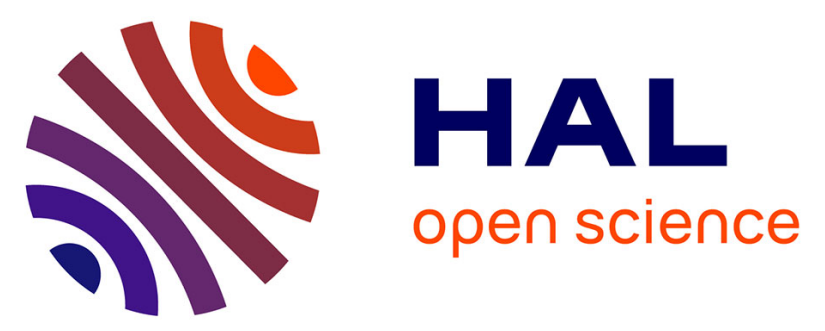

\title{
Internet of Things Integration in Supply Chains - An Austrian Business Case of a Collaborative Closed-Loop Implementation
}

\author{
Andreas Mladenow, Niina Maarit Novak, Christine Strauss
}

\section{To cite this version:}

Andreas Mladenow, Niina Maarit Novak, Christine Strauss. Internet of Things Integration in Supply Chains - An Austrian Business Case of a Collaborative Closed-Loop Implementation. 10th International Conference on Research and Practical Issues of Enterprise Information Systems (CONFENIS), Dec 2016, Vienna, Austria. pp.166-176, 10.1007/978-3-319-49944-4_13 . hal-01630547

\section{HAL Id: hal-01630547 https://hal.inria.fr/hal-01630547}

Submitted on 7 Nov 2017

HAL is a multi-disciplinary open access archive for the deposit and dissemination of scientific research documents, whether they are published or not. The documents may come from teaching and research institutions in France or abroad, or from public or private research centers.
L'archive ouverte pluridisciplinaire HAL, est destinée au dépôt et à la diffusion de documents scientifiques de niveau recherche, publiés ou non, émanant des établissements d'enseignement et de recherche français ou étrangers, des laboratoires publics ou privés. 


\title{
Internet of Things Integration in Supply Chains - An Austrian Business Case of a Collaborative Closed-Loop Implementation
}

\author{
Andreas Mladenow ${ }^{1, *}$, Niina Maarit Novak², Christine Strauss ${ }^{1}$ \\ ${ }^{1}$ University of Vienna, Department of e-Business, Faculty of Business, Economics \\ and Statistics, Oskar-Morgenstern-Platz 1 A-1090 Vienna, Austria, \\ andreas.mladenow@univie.ac.at; christine.strauss@univie.ac.at \\ ${ }^{2}$ Vienna University of Technology, Institute of Software Technology and Interactive \\ Systems, Favoritenstr. 9-11, A-1040 Vienna, Austria \\ niina.novak@ifs.tuwien.ac.at
}

\begin{abstract}
Although Internet of Things (IoT) applications exist since several years by now, only a very small amount of this applications are available on the market. Thus, there is still not much guidance on how to describe the evolution of cross-organizational IoT integration in a systematic manner. In this regard, we intent to make a contribution by analysing a business case, i.e. an ongoing IoT implementation of an Austrian retail trader. Hence, we elaborate on the type of integration for a cross-organizational integration of IoT, highlight the effects on companies and analyze the economic feasibility.
\end{abstract}

Keywords: IoT; Closed-Loop; Open-Loop; Cross Organizational Collaboration; Supply Chain; RFID.

\section{Introduction}

Recently, Cisco, the US based technology and software company, estimates that about 14 trillion dollars can be earned with the Internet of Things (IoT) until 2022 [1]. Mobility [2, 3], globalization and a society with a very diverse consumption and leisure behaviour cause increasingly complex of supply chains with a vast variety of customized goods, partially manufactured at multiple locations [4] and marketed worldwide [5]. This imposes particularly high demands on logistics providers [6] - which act as connecting elements in our increasingly integrated world [7]. Systems ought to be dynamic and flexible [8], but at the same time robust and cost-effective. The IoT provides a completely novel control architecture, which meets the described demand for highly flexible intralogistics systems and has thus the potential to shape the future of logistics in general [9].

Through IoT -applications and an increasing degree of self-organized supply chains it becomes possible that autonomously interacting objects and processes increasingly connect with the digital world of the Internet [10]. It is not a closed nor an independent 
system, but it includes a variety of different technologies, including radio networks, sensors and networks, microprocessors, tracking and tracing (T\&T) functions, Agent based Systems, Smart Labels, quick response (QR) codes or radio-frequency identification (RFID) [11]. As far as logistics are concerned, these technologies mark a paradigm shift [12]. Against this background, since many years intensive research and development is being invested to implement suitable IoT-applications for the logistics sector. As of today, the IoT as a technology is used partially and already offers significant benefits for users. T\&T systems offer the recipients of parcels the service to follow the progress and current status of a shipment while it is transported. This service is made possible via unique barcodes or 2D-codes which are scanned at specific transfer stations to uniquely identify a shipment, and to forward the current status automatically to a central data-system. This information about the current status can then be checked by the recipient of a parcel via a web-interface.

In the case of business collaborations [13], non-transparent and complex processes along the supply chain make it sometimes difficult to evaluate the economics gains of individual business partners $[14,15]$. Often the interests between partners differ greatly [16].

What are the potentials of IoT-based applications? Which holistic assessment methods are used along the supply chain to evaluate its economic efficiency? The corresponding evaluation deals with the performance-based distribution of costs and benefits along the supply chain, and with the necessary determination of target values for efficiency and resource allocation. Hence, the paper is structured as follows: the next section elaborates on the type of integration for a cross-organizational integration of IoT, highlights the effects on companies and deals with the economic feasibility. Section 3 analyzes an ongoing integration case, based on Siggelkow [17]. Afterwards, section 4 discusses relevant aspects. Section 5 summarizes the major findings of our ongoing research and gives a short outlook on future areas of research and likely developments.

\section{Background}

The demand to introduce cross-organization IoT-applications occurs foremost towards the end of the supply chain, at the retailer [18]. From an economical point of view, a decision in favor of IoT-applications leads at the same time to disadvantages resulting from a loss in subsidization for other important and strategic business projects related to achieving superordinate goals such as improving customer service satisfaction, innovation leadership [19] or in general company reputation [20].

\subsection{Type of integration}

The collaborative closed-loop IoT-Appliction allows for a cross-organizational implementation of systems and software along a supply chain, enabling access to all relevant data in order to ensure smooth operations and control of processes. These inherent features make it obvious that the use of collaborative closed-loops is particularly suitable for delivery networks, which are characterized by an intensive flow of materials. It allows for a particularly reliable, automated and real-time-based control of the material 
flow. Moreover, the IoT-application RFID is used at this level e.g. in the area of container management. These two applications are examples of the typical applications fields along a value-added network, namely trading networks with an exceptionally wide range of products or production networks with a particularly high number of individual components.

The open-loop system represents the most intensive interrelation across company boundaries. In addition to the integration of several companies as well the end user is included. For the end-user the integration into the collaborative closed-loop network is particularly beneficial as this allows to verify the origin and authenticity of a product. This is especially important in economic sectors (e.g. the pharmaceutical industry) with a fundamental and growing interest regarding product control and traceability. The open circuit is not only beneficial to the consumer, but has positive effects on the entire supply network. This is because the technology significantly reduces the workload for example in case of complaints or product recalls.

\subsection{External and internal effects on companies}

Related to the cross-organizational implementation and use, external and internal effects on the company have to be differentiated. While in the case of internal effects the potential benefits have a direct influence on the companies' processes, no direct relationship can be observed in the case of external effects. Through the automation effect a rationalization of manual work occurs in connection with data collection. The associated information effect guarantees that the company receives reliable information about the current position and state of items throughout the network at all time. As a consequence of the information effect another effect occurs, which is the transformation effect. This effect allows re-arranging processes in a more effective manner and leads to further reduced inventory costs. Improved transparency enables reductions in costs and inventory (especially safety stock as stock-levels and item locations can be monitored, as well as expected delivery times along the entire value-added chain without reducing the delivery service level).

Potential benefits can be triggered by both internal and external effects. In the case of external effects there are two main benefits, which positively influence project profitability, namely increased efficiency and savings [21] (in terms of fines resulting from various contract infringements). A substantial reason for this is the technically supervised commissioning of goods, which further enables an error free delivery. This has immediate positive effects on the number of incorrect deliveries, and thus on the number of fines for wrong or delayed deliveries. Another indirect cost reduction are regress payments which can be prevented through the complete documentation of manufacturing processes and the possibility to verify which materials and components have been used. This is particularly important for industries using voluntary or obligatory safety and authenticity certificates, e.g. in pharmaceutical industries, as well as other industries were safety regulations are of particular importance. At the same time product counterfeiting can be detected easier and faster, which in turn increases product-image safety. Moreover, administrative expenses in connection with product recalls can be either completely eliminated or at least reduced. 
Another external effect is the increase of efficiency and revenues caused by direct and indirect effects. Especially the shortening of processing times leads to increasing process efficiency. The avoidance and/or decrease of incorrect deliveries, further affects the reputation of the enterprise in a positive way, and thus contributes to an increase of customer orders.

The internal effects can be divided into three categories: (i) effects on upstreamprocesses, (ii) effects on downstream-processes, and (iii) effects on processes in other enterprises of the network. All three internal effects have in common that their potentials are exhausted when seizing the process components. At this point a superordinate potential is realized, as the collection and simultaneous generation of events is from now on done fully automatically rather than by hand.

The first type of internal effects is characterized by a positive influence on upstream-processes in a certain area, for example when taking a component from stock during the assembly process of a product, a production order is automatically triggered and forwarded to ensure that a new component is placed into stock in time. In the case of upstream-processes this results in less planning efforts as well as in a higher degree of machine utilization. The second internal effect, affects all downstream-processes. Thus, for example, with the acceptance of a new order, all downstream-processes are "informed" about the start of the manufacturing process of the new product, simply through the generation of a new event in the IoT-application. Following this, automatic actions are taken at the downstream-process locations, which increases process efficiency and leads to cost and time savings. This makes it possible that at the time of accepting a new order, necessary preparation procedures, e.g. related to the manufacturing process, could immediately start which avoids latencies and idle times. The third type of internal effects refers to various potential benefits realizable in the sphere of other partner enterprises in the supply chain.

All three types of internal effects have thereby a cost-minimizing influence on data management, the flow of material as well as on the degree of capacity utilization of the required production facilities. Savings related to data management result from automated data generation and data supply. The same is true for the flow of materials, where automated processes lead to a rationalization of manual, expensive and inefficient activities, and thus to a more efficient use of existing resources. This leads to better process planning and ultimately to a reduction of production resources. Moreover, due to an increased efficient use of the equipment further costs for example for storage or transportation vehicles can be reduced. In contrast to external effects, the identification of benefits related to internal effects greatly depends on the chosen IoT implementation, which is the reason why these effects cannot be identified easily on a general level.

\subsection{Economic feasibility for the integration of cross organizational IoT- applications}

Regarding the economic feasibility, a clear distinction for reallocation is made between both, performance-based as well as non-performance-based strategies for cross organizational IoT integration. 
The performance-based strategy contains a value-dependent profit allocation: in this case, the generated profit of a project is shared among the participants based on the contribution (value-added share) of each contributor to the product. This strategy implies that companies, which do not perform direct value-adding activities, such as logistics service providers, are neglected during the profit allocation process. This problem can only be solved via individually negotiated profit-share allocations. At the same time, the expenses incurred by a company cannot be directly concluded from the company's share of value-added to a product. Therefore companies may suffer losses, if the costs are higher than the share of value-added.

Furthermore, the performance-based strategy implies an identical return on investment. This is a redistribution strategy, where each partner generates the same return on investment. This means that the profit allocation is based on the expenses incurred. Due to this expense-oriented calculation of return on investment, each company receives exactly the return of investment of the entire project. The advantage of this approach is thus to have a consistent return of investment throughout the entire network, which in turn increases the chances of a fast agreement between different company-partners and enables a fast implementation of the project.

On the other hand, the non-performance based strategy entails the compensation of losses. Those companies that suffer any losses due to a certain project, receive a compensation in the same amount. This implies that at least one partner benefits, as the positive net present value of the project is allocated to him due to the zero profit of the others. Therefore, it is ensured that none of the partners is worse off after the project than he was before.

In addition, the non-performance based strategy implies identical target allocation. The aim of this approach is to redistribute the relative impacts of the project (i.e. comparison of costs and benefits, which can only be positive, as the project wouldn't have been implemented otherwise), among the project partners, in such a way that each company generates the same profit in that specific project. In the case of a positive network effect, the total profit increases with the number of participants - e.g. as it is the case in many supply chains - this implies a win-win situation.

Besides, there is an identical profit allocation. The profits of all partners of the project are summed up, and subsequently evenly redistributed to all project partners, regardless of other factors. This approach might thus lead to losses for some of the project partners, provided that the received profits do not cover the expenses incurred. Therefore, this approach entails a non-negligible probability of ending up in a win-lose situation for some of the project-partners, which in turn may result in refusing to participate in the project.

In order to distribute costs and benefits in a fair manner along the supply chain a cost-benefit-sharing approach may be performed. By means of introducing a neutral instance, a basis for detecting and documenting company-specific and network-related costs and benefits, is being established. This contributes proposals for a fair distribution of investments and/or savings, without disclosing company-specific key figures to partner companies.

What are the costs and benefits of individual companies using standardized process modules and impact factors such as internal transport, material processing, storage and 
retrieval? Indicators which are worth reviewing include the overall profitability, cash flows and valuation records. Indicators which are relevant for forecasting include structural as well as quantity related indicators, efficiency indicators, quality metrics, and IoT impact indicators. Best practices of IoT-applications such as RFID include [20]:

- identification of relevant impact factors in terms of costs, and definition of standardized process modules for overall supply chain processes

- allocation of relevant factors to costs and benefits.

- determination of target values for the assessment and evaluation of a cost model

- integration of the identified benefit for companies in the cost model

- individual evaluation of the economic efficiency of the use of IoT-applications for companies involved in the value-added process

- balancing of interest-asymmetries by methods of cost-benefit-sharing and by including a neutral instance.

\section{Analysis of an Austrian Retail Trader Business Case}

Based on Siggelkow [17], we analyse an ongoing case of a cross-organizational, "things orientated" [10] IoT integration. The Austrian retail trading company has implemented a collaborative closed-loop RFID system with its tier-1 supplier. Moreover, it is presently being discussed, how additional IoT-applications could be integrated to both, the customer and tier-2 suppliers within the supply chain as depicted in Figure 1.

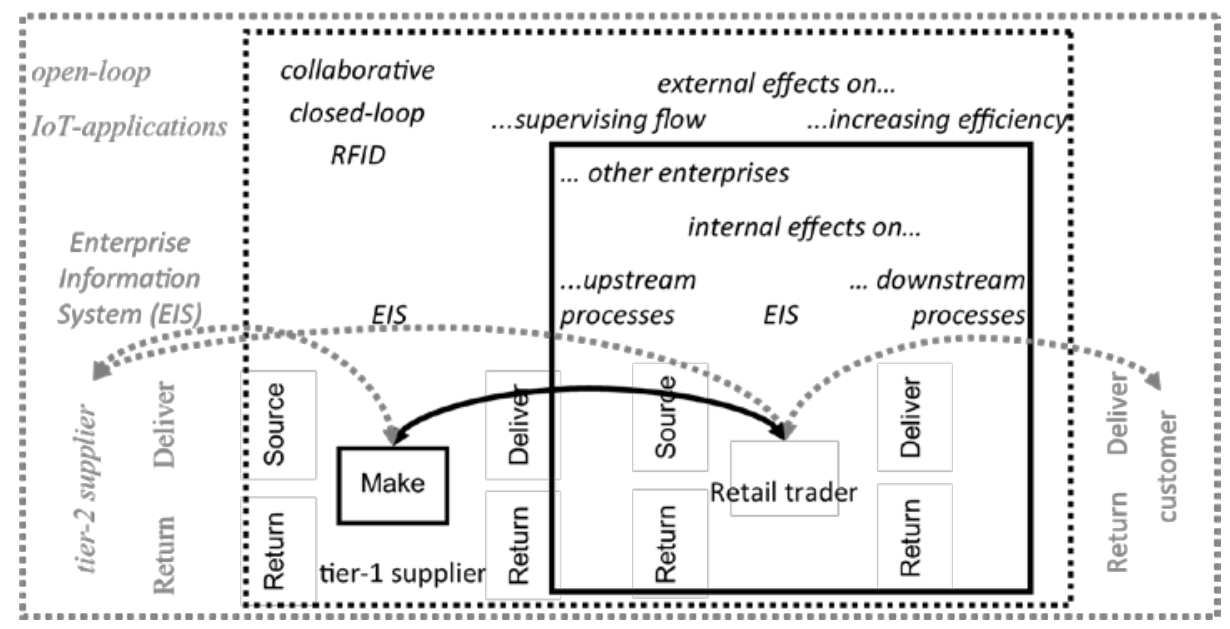

Fig. 1. Cross-company collaborative closed-loop implementation of an IoT-application

Furthermore, the concept of Vendor Managed Inventory (VMI) is applied in parallel to a cross-organizational use of IoT-applications by multiple, cooperating business partners. VMI serves as an incentive instrument for the supplier. 
Moreover, for the tier-1 supplier it is obligatory to buy back all products that could not be sold from the retailer at full price. Therefore, the supplier has to take the entire risk in case of overproduction. Thus, the agreement has a similar effect like an incentive for retailers to increase their inventory to avoid stock-outs. Higher inventory levels imply less stock-outs - ultimately this is beneficial for the entire supply chain and thus also for customers.

In the case of VMI the manufacturer is responsible for the inventory management of the retailer. Therefore, the retailer pays only for those goods which have been actually sold. The supplier is thus forced to cover any costs in order to make improvements in his own warehouse - not in the warehouse of the retailer. In this context, it is often necessary to acquire the necessary and appropriate competencies, infrastructure and know-how at first.

In addition, the customer's demand of goods depends on the price; and the retailer's (who in turn is a customer of his supplier) demand depends on the demand of his customers and the price. Hence, the risk reduction effect caused by a sub-optimal inventory level (higher or lower than the optimal inventory level) - lost profits and/or turnover or sunk costs - causes automatically a reduction of costs on the retailer's side, which in turn reduces the prices for goods. Consequently, the consumer's price elasticity increases the retailers' demand of goods, which in turn is beneficial for the entire supply chain.

Such contractual agreements, however, do not only influence the rights of disposal in the retailer's warehouse, but also the quality of inventory management. The application of IoT in a VMI-implementation may not only generate cost advantages, but may also positively affect the relationship between the contracting parties, the efficiency of inventory management, the accurateness of the order policy, as well as the automatic recognition of expired products. Especially for suppliers who sell multiple products, an efficient inventory management system is of utmost importance; such system supports efficient use the shelf-space provided by the retailer, Furthermore, the supplier is able to improve his turnover in a specific shop or location. VMI particularly enables and suggests the display of additional products or an alternative product-mix at a certain retailer.

In the present case, the use of an IoT-application seems to be disadvantageous for the supplier due to various reasons, leading to the fact that the use of IoT is less profitable for the supplier than for the retailer without a pre-defined, appropriate compensation for the supplier. When receiving goods, the suppliers' effort can be reduced considerably.

Even once a production process has finished, there are hardly any benefits or savings for the supplier due to the fact that many suppliers produce only one single producttype or a limited number of different products. Furthermore, products are typically packed and stored in standardized dimensions, quantities and carriers. In addition, suppliers typically supply several different customers (i.e. wholesalers and retailers), of which, however, only few use the IoT-application. Thus, even though the supplier takes over a large part of the IoT-application's costs, he hardly ever has the possibility to benefit from the full potential of the technology in terms of profit. Unlike the suppliers, retailers benefit from IoT-applications from the very beginning. For example, activities 
associated with stock receipt can be significantly reduced during receipt (i.e. bulk dispatch): once the goods are received, the IoT-technology allows for further simplifications for example in connection with the storing process in form of automated storage space allocation and its registration in the database.

The use of IoT-systems further supports the order-picking and outsourcing process not only through the automatic registration of products, but also by providing a security control function [22] during the loading of ordered goods, which automatically rechecks whether the right goods are being loaded into the right truck. This reduces the number of incorrect deliveries and commissioning, which ultimately allows for cost savings associated with the returns of goods and redeliveries. Even before the receipt of goods or after a successful delivery of goods the retailer may profit from the use of a IoT-application. Using real-time tracking and condition monitoring (e.g., temperature control for perishable goods), it is possible to detect delays or cooling unit failures at an early stage, which allows the person in charge to react in time and to find appropriate alternative solutions [23].

Moreover, the Electronic Product Code (EPC)/RFID-Calculator, an open source Tool (based on visual basic for excel), is used to determine the economic feasibility for the cross-organizational IoT-application integration [24].

\section{Discussion}

IoT-implementations are increasingly applied in cross-organizational supply chains [25]. Worldwide, millions of items are being moved every day, ranging from huge containers, over pallets to individual parcels. In order to ensure a smooth processing, it is of outmost importance that items arrive at the right place at the right time [26]. Manual processes (such as counting of containers before they are loaded on board of an aircraft), should be increasingly replaced by self-controlled systems and thus by smart IoT-applications which are integrated and therefore connected to each other [27]. Similar to internet data packets, when using IoT-applications shipments control and navigate through the logistics networks by routing themselves on their own [28]. The logistics service provider is subsequently informed that all shipments are being transported [29]. From the perspective of a company this results in a considerable increase of efficiency [30]. However, these economic gains in supply chains are not always equally distributed among the players in the supply chain [31].

Concerning economic feasibility, a distinction should be made between personnel expenses and expenses for resources. In addition, there is a distinction between onetime and current expenditures. The use of time and resources related to a specific process are identified and evaluated. The identified effects are quantified; expenditures and potential benefits must be documented accordingly. In particular, expenditures related to the use of technology and which might cause additional cost must be documented and shown. The result is a cost model focusing on capital value and payback time, which is used to determine the profitability in case of uncertainty. This allows to assess 
the overall effect of use across organizational borders. In addition, an expansion analysis can be carried out, which analyzes the essential factors for the use of IoT-applications such as RFID [20].

Atzori et al. [10] distinguish between "semantic"-, "internet"-, and "things"-orientated IoT visions. In this regard, partners of cross-organizational collaborations already benefit from new promising developments in these areas [32]. On that score, the shared information hub (SIH) and the total supply chain visibility (TSCV) support IoT-applications for supply chains.

SIH is a tool aimed at simplifying and improving data exchange, providing a solution for the typical problems of supply chain management [33]. Due to a lack of data exchange, individual players in a supply chain usually perform their business planning on different assumptions, which result in a gradual and downstream domino effect ("informational Domino Principle"). Accordingly, the so-called bullwhip effect can be mitigated or even prevented [34]. Using the SIH allows for cross-organizational and integrated planning in the context of supply chain management, based on a shared data pool. This approach is made possible through the use of IoT-applications, which provide real-time and automated information to all parties involved along the entire supply chain. In this way potential delivery delays, problems or even failures can be detected early on (e.g., the failure of a container's cooling unit in the food industry), long before it would have been possible with a conventional communication strategy. This allows that supply chain members can react early on and with the purpose of finding alternative and appropriate solutions in time.

The TSCV approach is an ICT solution allowing members of a complex value network to improve, intensify and automate their communication among each other. This makes it possible to restructure, improve and cut out previously inefficient process steps, which results in a more efficient use of available resources and higher performance. In addition, the improved coordination and communication between the business partners leads to a closer degree of collaboration and integration along the supply chain; this may positively affect the level of trust. Especially with regard to cooperation and joint projects, these network effects and ties play an important role for cross-organizational collaborations.

\section{$5 \quad$ Conclusion and Outlook}

In this paper we analyzed the integration of a "things"-orientated IoT-application [10] for an Austrian cross-company collaboration. The retailer perceives the IoT-application on the supplier side as a competitive advantage compared to other suppliers. For the retailer the use of the IoT-technology implies both cost savings and a higher performance level. For these advantages retailers are willing to pay a higher price to suppliers or even decide to cooperate exclusively with suppliers that use IoT-applications.

At present, the integration of cross-organizational IoT-applications is still in its infancy, as a huge number of novel applications emerge on the market. Consequently, numerous concepts are implemented, which lead to a reorganization and new division of tasks and competencies of both manufacturers and their customers. In terms of crossorganizational collaboration, increased benefit can be achieved only if IoT-applications 
are being used across organizations, and only if the costs can be allocated to the individual partners of the supply chain. In this regard, a survey with multiple retailers shall be conducted to obtain quantified results, which can be used as a basis for future research. Hence, scenarios should be examined appropriately and accordingly to keep the risk of an IoTimplementation as low as possible.

\section{References}

1. Columbus L., in Forbes, retrieved on 25. 08.2016

from http://www.forbes.com/forbes/welcome/?toURL=http://www.forbes.com/sites/louiscolumbus/ 2015/12/27/roundup-of-internet-of-things-forecasts-and-market-estimates-2015/\&refURL=https://www.google.at/\&referrer=https://www.google.at/

2. Mladenow, A., Novak, N. M., \& Strauss, C. (2015). Mobility for 'Immovables'-Clouds Supporting the Business with Real Estates. Procedia Computer Science, 63, 120-127.

3. Hyben, B., Mladenow, A., Novak, N. M., \& Strauss, C. (2015, December). Consumer acceptance on mobile shopping of textile goods in Austria: modelling an empirical study. In Proceedings of the 13th International Conference on Advances in Mobile Computing and Multimedia. ACM, 402-406.

4. Mladenow, A., Bauer, C., Strauss, C., \& Gregus, M. (2015, September). Collaboration and Locality in Crowdsourcing. In Intelligent Networking and Collaborative Systems (INCOS), 2015 International Conference on IEEE, 1-6.

5. Cheng, Y., Tao, F., Xu, L., \& Zhao, D. (2016). Advanced manufacturing systems: supplydemand matching of manufacturing resource based on complex networks and Internet of Things. Enterprise Information Systems, 1-18.

6. Mladenow, A., Bauer, C., \& Strauss, C. (2015, December). Crowdsourcing in logistics: concepts and applications using the social crowd. In Proceedings of the 17th International Conference on Information Integration and Web-based Applications \& Services. ACM, 30.

7. Mladenow, A., Bauer, C., \& Strauss, C. (2016). 'Crowd Logistics': The Contribution of Social Crowds in Logistics Activities. International Journal of Web Information Systems, 12(3), Elsevier, 379-396.

8. Makarova, T., Mladenow, A., \& Strauss, C. (2016). Barrierefreiheit im Internet und Suchmaschinenranking - eine empirische Untersuchung. Informatik 2016. Nr. 259, Lecture Notes in Informatics, Gesellschaft für Informatik, Köllen Druck. Bonn, 1071-1086.

9. Speranza, M. G. (2016). Trends in transportation and logistics. European Journal of Operational Research.

10. Atzori, L., Iera, A., \& Morabito, G. (2010). The internet of things: A survey. Computer networks, 54(15), 2787-2805.

11. Whitmore, A., Agarwal, A., \& Da Xu, L. (2015). The Internet of Things-A survey of topics and trends. Information Systems Frontiers, 17(2), 261-274.

12. Guo, B., Zhang, D., Wang, Z., Yu, Z., \& Zhou, X. (2013). Opportunistic IoT: Exploring the harmonious interaction between human and the internet of things. Journal of Network and Computer Applications, 36(6), 1531-1539.

13. Mladenow, A., Bauer, C., \& Strauss, C. (2015, September). Collaborative Shopping with the Crowd. In International Conference on Cooperative Design, Visualization and Engineering. Springer International Publishing, 162-169. 
14. Werner, H. (2013). Supply Chain Management: Grundlagen, Strategien, Instrumente und Controlling. Springer-Verlag.

15. Beamon, B. M. (1999). Measuring supply chain performance. International journal of operations \& production management, 19(3), 275-292.

16. Bensel, P., Gunther, O., Tribowski, C., \& Vogeler, S. (2008). Cost-benefit sharing in cross-company RFID applications: a case study approach. ICIS 2008 Proceedings, 129.

17. Siggelkow, N. (2007). Persuasion with case studies. Academy of management journal, 50(1), 20.

18. Attaran, M. (2012). Critical success factors and challenges of implementing RFID in supply chain management. Journal of Supply Chain and Operations Management, 10(1), 144167.

19. Novak, N. M., Mladenow, A., \& Strauss, C. (2013, December). Avatar-based Innovation Processes-Are Virtual Worlds a breeding ground for Innovations?. In Proceedings of International Conference on Information Integration and Web-based Applications \& Services. ACM, 174.

20. Irrenhauser, T., \& Reinhart, G. (2014). Evaluation of the economic feasibility of RFID in the supply chain. Production Engineering, 8(4), 521-533.

21. Widhalm, M., Mladenow, A., \& Strauss, C. (2015). E-Appointment Plattformen zur Effizienzsteigerung und Umsatzgenerierung-eine Branchenanalyse. HMD Praxis der Wirtschaftsinformatik, 52(3), 401-417.

22. Mladenow, A., Novak, N. M., \& Strauss, C. (2015, October). Online Ad-fraud in Search Engine Advertising Campaigns. In Information and Communication Technology-EurAsia Conference. Springer International Publishing, 109-118.

23. Richards, G., \& Grinsted, S. (2016). The Logistics and Supply Chain Toolkit: Over 100 Tools and Guides for Supply Chain, Transport, Warehousing and Inventory Management. Kogan Page Publishers.

24. EPC/RFID-Calculator retrieved on 01. 08.2016 from https://www.google.at/url?sa=t\&rct= $\mathrm{j} \& \mathrm{q}=\&$ esrc $=$ s\&source=web\&cd $=1 \& \mathrm{cad}=\mathrm{rja} \& u a c t=8 \& v e d=0$ ahUKEwjrqtrCpfPOAhVJBSwKHXat BkAQFgghMAA\&url=http\%3A\%2F\%2Focw.mit.edu\%2 Fcourses\%2Fengineering -systems-division\%2Fesd-290-special-topics-in-supply-chain-management-spring2005\%2Ftools\%2FEPCRFID CalculatoMarch2005.xls\&usg=AFQjCNHf8D0N0HR4nQ7Hzcdphmxu2PG_vg

25. Li, S., Da Xu, L., \& Zhao, S. (2015). The internet of things: a survey. Information Systems Frontiers, 17(2), 243-259.

26. Christopher, M. (2016). Logistics \& supply chain management. Pearson Higher Ed.

27. Welbourne, E., Battle, L., Cole, G., Gould, K., Rector, K., Raymer, S. \& Borriello, G. (2009). Building the internet of things using RFID: the RFID ecosystem experience. IEEE Internet Computing, 13(3), 48-55.

28. Uckelmann, D., Harrison, M., \& Michahelles, F. (2011). An architectural approach towards the future internet of things. In Architecting the internet of things. Springer Berlin Heidelberg, 1-24.

29. Bi, Z., Da Xu, L., \& Wang, C. (2014). Internet of things for enterprise systems of modern manufacturing. IEEE Transactions on Industrial Informatics, 10(2), 1537-1546.

30. Kärkkäinen, M. (2003). Increasing efficiency in the supply chain for short shelf life goods using RFID tagging. International Journal of Retail \& Distribution Management, 31(10), 529-536. 
31. Gelsomino, L. M., Mangiaracina, R., Perego, A., \& Tumino, A. (2016). Supply chain finance: a literature review. International Journal of Physical Distribution \& Logistics Management, 46(4), 348-366.

32. Leminen, S., Westerlund, M., Rajahonka, M., \& Siuruainen, R. (2012). Towards iot ecosystems and business models. In Internet of Things, Smart Spaces, and Next Generation Networking. Springer Berlin Heidelberg, 15-26.

33. Usländer, T., Berre, A. J., Granell, C., Havlik, D., Lorenzo, J., Sabeur, Z., \& Modafferi, S. (2013, October). The future internet enablement of the environment information space. In International Symposium on Environmental Software Systems. Springer Berlin Heidelberg, 109-120.

34. Rogers, H., El Hakam, T. A., Hartmann, E., \& Gebhard, M. (2015). RFID in Retail Supply Chains: Current Developments and Future Potential. In Logistics Management. Springer International Publishing, 201-212. 